\title{
Doğuştan çarpık ayak tedavisinde Ponseti yöntemi uygulama prensipleri
}

\section{Application principles of Ponseti method in the treatment of congenital clubfoot}

\author{
Mustafa Işık, Mehmet Subaşı, Burçin Karslı \\ Gaziantep Üniversitesi Tıp Fakültesi, Ortopedi ve Travmatoloji Kliniği, Gaziantep
}

Pes ekinovarus, ayakta en sık görülen doğumsal şekil bozukluğudur. Etiyolojisi tam olarak tanımlanmamış olmakla birlikte, çeşitli faktörlerin etiyolojide yer aldığı bilinmektedir. Klinik muayene ile kolayca tanınabilir. Tedavi konusunda, geçmişten günümüze kadar çeşitli görüşler ve uygulamalar bulunmaktadır. Uygulanan cerrahi tedavilerden sonra skar doku oluşumu ve sert eklem oluşumu nedeniyle, konservatif yaklaşımlar zamanla daha popüler hale gelmiştir. Günümüzde pes ekinovarus tedavisinde kullanılan konservatif yöntemlerden en çok tercih edileni Ponseti metodudur. Bu yöntemle, haftalık seri alçılamalar yapılarak deformitenin düzeltilmesi ve fonksiyonel iyileşmenin elde edilmesi amaçlanmaktadır. Ponseti yöntemiyle, prensiplerine bağlı kalınarak uygulandığında, mükemmel sonuçlar elde edilmektedir.

Anahtar sözcükler: pes ekinovarus; Ponseti metodu; konservatif tedavi
Pes equinovarus is most commonly seen congenital foot deformity. Although the etiology is not identified exactly it is known that various factors have roles in it. It can be diagnosed with physical examination easily. From past to present, several concepts and modalities are practiced for treatment. Conservative treatment options became popular in the course of time because of scar tissue and joint stiffness observed after surgical procedures. Recently, Ponseti method is the most preferred conservative technique for the treatment of pes equinovarus. The aim of this method is correcting deformities, and achieving functional healing by serial casting weekly. Excellent results can be achieved with Ponseti method if the technique is applied adhering to the principles.

Key words: pes equinovarus; Ponseti method; conservative treatment

\section{P} es ekinovarus (PEV), ayakta en sık görülen doğumsal şekil bozukluğudur. Hastalığın etiyolojisi tam olarak bilinmemekle birlikte multifaktöriyel etkileşimlerin olduğu bilinmektedir. ${ }^{[1,2]}$ Genetik özellikler, embriyolojik gelişimin bir noktada durması, talus kıkırdağında plazma germ hücre defekti, suçlanan faktörlerden sadece birkaçıdır. ${ }^{[3]}$ Ancak, intrauterin hacmin azaldığı durumlarda (çoğul gebelik, oligohidroamnioz vb.) görülme sıklığının arttığı gösterilememiştir. ${ }^{[4]}$

Patolojik anatomi denilince akla bağ, kapsül ve tendonların kontraktürüyle birlikte, talusun navikula ve diğer tarsal kemiklerle olan bozulmuş ilişkisi, kavus ve internal tibial torsiyon akla gelir. ${ }^{[5]}$

Genellikle diz ekleminin distalinde kalan ve özellikle ayak bileği çevresindeki tüm yapıların birlikte etkilendiği bir hastalıktır. Yani, sadece kemik yapı değil, beraberinde osteoartiküler yapılar, muskülotendinöz oluşumlar, bağlar, nörovasküler yapılar ve hatta cilt bile etkilenir (Şekil 1). Bu nedenle, tedavi planlaması yapılırken, hem yumuşak dokuyu hem de kemik-eklem ilişkilerini düzeltebilmek amaçlanmalıdır. PEV hastalarında tanı için fizik muayene genelde yeterli olmakla birlikte, ayrıcı tanılar ve takip sürecinde radyolojik tanı metodları da kullanılabilir. ${ }^{[6]}$

\section{TEDAVi}

Büyümekte olan ayağın kompleks patolojik anatomisi nedeniyle, çocuklarda PEV tedavisi zordur. Tedavide amaç, yere düzgün basan fonksiyonel bir ayak elde etmektir. Günümüzde bu amaca ulaşmak için kabul edilen görüş, tedaviye mümkün olduğu kadar erken başlanması yönündedir. ${ }^{[7]}$ Yenidoğan ayağının viskoelastik özelliği nedeniyle, erken tedavi başarı oranını arttırmaktadır. Yine kabul edilen ve uygulanan bir diğer

- Illetişim adresi: Doç. Dr. Mustafa Işık, Şahinbey Uygulama Hastanesi, Ortopedi Polikliniği, Üniversite Bulv. Şahinbey, Gaziantep Tel: 0533 - 6361796 e-posta: drmustafaisik@yahoo.com

- Geliș tarihi: 25 Mayıs 2015 Kabul tarihi: 25 Mayıs 2015 


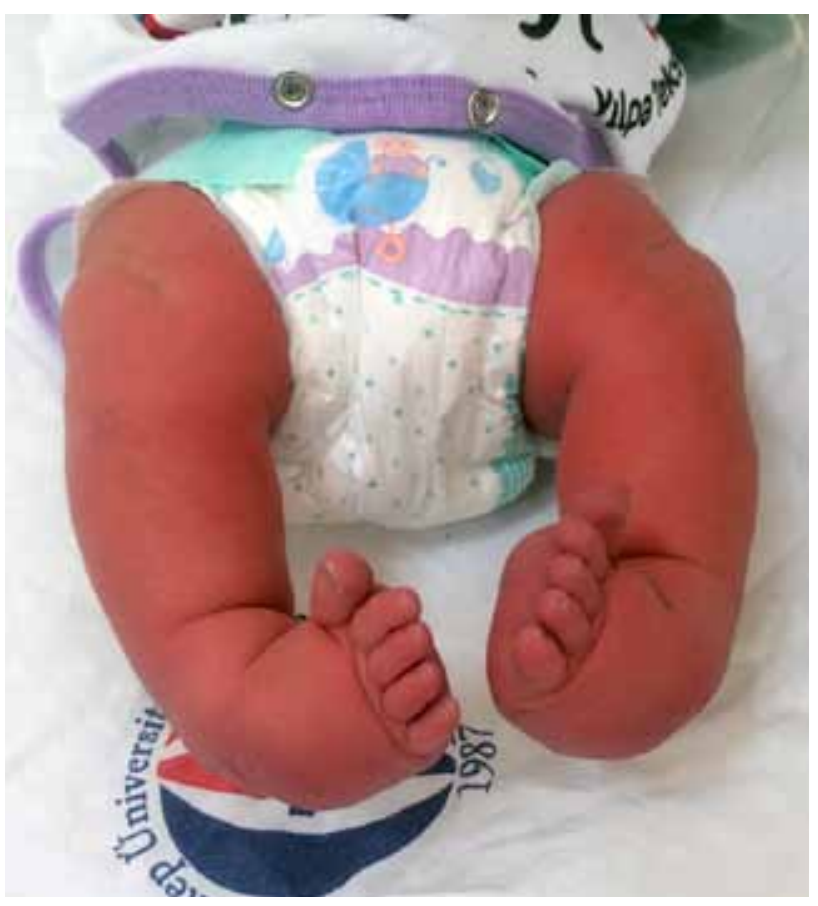

Şekil 1. Doğuştan çarpık ayak klinik görünümü.

görüş, öncelikli tedavinin cerrahi dışı yöntemler olması gerektiğidir. Cerrahi dışı tedavi başarılı olduğu takdirde, kesin tedavi sağlanmış olacaktır. Başarılı olmadığı takdirde ise, cerrahi sonrası görülebilen skar oluşumu ve eklem sertliği gibi problemleri en az seviyeye indirme etkisi nedeniyle, yine ilk tercih edilecek yöntem cerrahi dışı tedavi olmalıdır. Erken dönemde uygulanan cerrahi sonrasında gelişebilen skar dokunun fazla olduğu ve eklem sertliğinin daha sık görüldüğünü bildiren çalışmalar mevcuttur. ${ }^{[8]}$

Ponseti metodunun kullanılmaya başlamasından önceki dönemde; Kite, 1924-1960 yılları arasında, manipülasyon ve alçılama ile tedavi ettiği 800 çocukta elde ettiği başarılı sonuçları bildirerek, cerrahi dışı tedaviyi önermiştir.1940'lı yıllarda ise, Dr. Ignacio Ponseti, PEV hastaları için uyguladığı kendi tekniğini geliştirmiştir. ${ }^{[9]}$

\section{PONSETI YÖNTEMi}

Ponseti de Kite gibi, cerrahi yöntemlerle görülme oranı artan skar ve eklem sertliği gibi komplikasyonları azaltmaya yönelik, daha az agresif davranma yollarını araştırmış ve yenidoğanlarda yaptığı anatomik disseksiyon çalışmaları, PEV pato-anatomisini anlamada çok önemli katkılar sağlamıştır. ${ }^{[9]}$ Kollajen biyolojisi ile ilgili araştırmaları da, kademeli düzeltme uygulamalarının temelini oluşturmuştur. Yaptığı haftalık düzeltme alçılarıyla, kollajen yapıların rahatlamasına ve eklem yüzeyinin atravmatik remodeling'ine yardımcı olmuştur. ${ }^{[10]}$ Böylece, cerrahi tedavi komplikasyonları olan skar doku gelişimi ve eklem sertliğinden kurtulmuştur. Ayrıca, bu yöntemle \%95 oranında posterior, mediyal veya lateral gevşetmelere gereksinim duyulmadığını rapor etmiştir. ${ }^{[11,12]}$ Günümüzde yaygın olarak kullanılan Ponseti metodunun etkili olabilmesi için, tedavi sürecinin bazı prensiplere uyularak ilerlemesi gerekir.

\section{PRENSIPLER}

PEV deformitesi Ponseti metoduyla tedavi edilecekse, öncelikle tedaviye engel bir durum yoksa, buna mümkün olan en erken dönemde başlamak gerekir. [13] Çünkü, bu metodun hem yumuşak doku hem de osteoartiküler yapılar için remodeling kapasitesi çok yüksektir.

Haftalık yapılan düzeltme alçılarının belli bir sıraya göre yapılması önemlidir. Illk olarak kavus, sonra adduktus, daha sonra varus ve en son olarak ta ekin deformiteleri düzeltilmelidir. ${ }^{[6]}$

Alçlamaya başlamadan önce, bağları uzatmaya ve deformiteyi düzeltmeye yönelik olarak 1-3 dakika boyunca manipülasyon yapmak gerekir.

Yapılan alçı, ayak başparmağından femur proksimaline kadar uzatılmalıdır. Bu sırada dizin $90^{\circ}$ fleksiyonda olmasına özen gösterilmelidir. Beş ya da altı düzeltme alçısı, çoğu PEV hastasında etkin düzelme sağlayabilmektedir.

Bebeğin alçılama öncesinde beslenmesi, alçılama sırasında bacaklarını kasmaması ve rahat olması için yararlı olur. Böylece daha rahat alçılama yapılabilir.

Yenidoğanda görülen kavus, yumuşak karakterdedir. Düzeltme alçılamalarında ilk hedef ise, bu yumuşak kavusu düzeltmektir. Bu nedenle, ilk alçıda ayak önünü arkasına göre göreceli olarak supinasyona getirmek gerekir. Ayak önü supinasyona getirildikçe, ayak arkasıyla aynı hizaya geldiği ve arkın normalleştiği görülebilir. Deformiteyi düzeltmek için ortopedistin ayağı pronasyona getirmesi, iyatrojenik olarak deformiteyi daha da arttıran yanlış bir uygulamadır. ilk alçılamayla metatars başının eleve edilmesi ve ayak önünün supinasyon ve abduksiyona getirilmesi ile, kavus deformitesi neredeyse her zaman düzelir.

Başarılı bir manipülasyon ve alçılama periyodu için, kavus düzeltildikten sonra metatars adduktus, topuktaki varus ve inversiyon eş zamanlı düzeltilmelidir. Çünkü, ayak bileği eklemlerinin birbirine bağımlı ve sıkı bir ilişkisi vardır.

Manipülasyon, ayağı talus altından abduksiyona zorlayarak deformiteyi düzeltmeye çalışmak şeklinde tanımlanabilir. Bebeği rahatsız etmeden, ayak iyice 


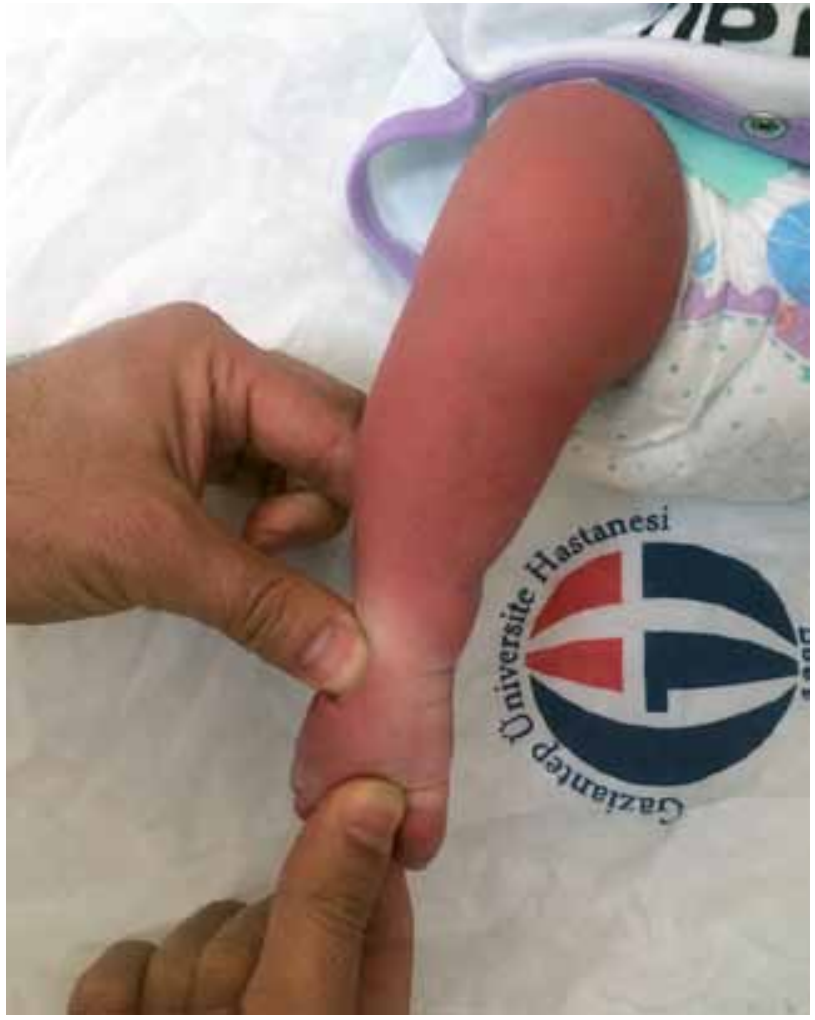

Şekil 2. Talus başına baskı uygulayarak yapılan manipülasyon.

abduksiyona getirilerek 1 dakika kadar beklenir. Talus başını bulmak için, lateral malleolün anteriorunu palpe etmek yeterli olabilir. Daha inferiorda, kalkaneusun ön yüzü de palpe edilebileceği için, talus başı ve kalkaneus ön yüzü karıştırılmamalıdır. Eş zamanlı olarak yapılacak düzeltmeler için talus başına başparmakla lateralden baskı yapılırken, ayak ön kısmı diğer el yardımıyla mümkün olduğunca abduksiyona getirilir (Şekil 2). Bu manevrayla, mediyale deplase halde bulunan navikula ve küboid ile birlikte kalkaneus da kademeli olarak laterale doğru yer değiştirecektir. Bu anahtar manevra, deformitede majör düzelme sağlar. Ayak abduksiyona zorlanırken talus başına yapılan baskı sayesinde, posterior kalkaneofibular bağın gerilmesi önlenir. Bu sayede, fibula posteriora doğru yer değiştirmez. Usule uygun yapılan 3-4 alçılama, mediyaldeki tarsal bağ yapılarının gevşemesini ve eklemin redükte olmasını büyük oranda sağlayacaktır. İlk alçılamayla kavus düzeltilirken, 2.-4. alçlamalarda kademeli olarak adduktus ve varus düzeltilir. Her alçıdan sonra, ayak supinasyonu kademeli olarak azalacaktır. Çok sert ayaklarda düzelmeyi sağlamak için, daha fazla alçılama gerekebilir. ${ }^{[14]}$

Bu düzeltmeler uygulanırken, topuk asla dorsifleksiyona zorlanmamalıdır. Ayak bileği ekindeyken ayak önü abduksiyona getirilmeye çalışılmalı ve böylece kalkaneusa dokunmadan, talusun altından kayarak abduksiyona gelmesine izin verilmelidir.

Ayak arka kısmının varusu tam düzeltilmeden, topuk dorsofleksiyona zorlanmamalıdır. Aksi halde, rockerbottom deformitesi gelişmesine yol açılabilir. Bu noktada dikkatli olunmalıdır.

Ekin deformitesi, en son düzeltilmesi gereken deformitedir. Topuk nötrale veya hafif valgusa, ayak ise $70^{\circ}$ kadar abduksiyona gelmeden, topuk dorsifleksiyona zorlanmamalıdır. Abduksiyonun $70^{\circ}$ olması fazla gibi görünse de, rekürrensi önlemek için gereklidir.

Ekin deformitesi düzeltilirken, tüm ayak tabanı boyunca basınç uygulanmalıdır. Sadece metatars başlarından uygulanan basınç, rocker-bottom deformitesine yol açabilir.

Progresif uzatma manipülasyonları ve alçılamalarla, ekin deformitesi de düzeltilebilir. Esnek PEV'lerde ekin düzeltmesi daha kolay olsa da, şüpheye düşülen durumlarda çekinmeden tenotomi yapılmalıdır. Ancak, daha hızlı ve etkili bir ekin düzeltmesi için, hastaların büyük bir kısmında (\%85) subkutan Aşil tenotomisi gerekir. Bir yaşına kadar yapılan tenotomilerde, aşırı uzama veya güçsüzlük gibi istenmeyen etkiler görülmez. ${ }^{15]}$

\section{ALÇI UYGULAMASI}

Alçılamaya başlamadan önce, yukarıda anlatıldığı şekilde 1-2 dakika esnetici manipülasyon yapılmalıdır. Maksimum düzelme sağlandıktan sonra, ayak parmaklarından tutularak ince bir kat pamuk sarılır. Alçı, ayak parmakları çevresinde 3-4 tur sarıldıktan sonra proksimale uzatılıp, diz altında sonlandırılır; daha sonra uyluk proksimaline kadar uzatılır. Sadece kısa bacak alçısı şeklinde uygulamalardan kaçınmak gerekir. Parmakları tutan kişinin parmakları üzerinden sarılan alçı, parmak uçlarını görmek için yeterli boşluk oluşmasını temin edecektir.

Alçıya şekil verirken aşıı kuvvetten kaçınılmalı, hafif basınç uygulanmalıdır. Talus başına sabit baskı yapılmamalı, tekrarlayan basma-gevşetme ve sıvazlama hareketleri yapılmalıdır. Alçı vurmasını engellemek için, alçının talus başına ve kalkaneal bölgeye iyice oturtulması gerekir. Düztabanlı̆̆ı ve kayık ayak deformitesini önlemek için de, alçının mediyal ayak arkına iyice oturtulması gerekir. Alçı sertleşene kadar, ne kalkaneusa ne de başka bir bölgeye sabit basınç uygulanmamalıdır. Alçı için dinamik bir donma süreci sağlanmalıdır. Alçı donana kadar, sıvazlayarak şekil verilmeye devam edilmelidir. Ayak parmaklarının alttan desteklenmesi için, plantar bölgedeki alçının bırakılıp, dorsal bölgedeki alçının ise birazcık açılması, parmak dolaşımlarını takip etmek için yararlı olacaktır. ${ }^{[16]}$ 

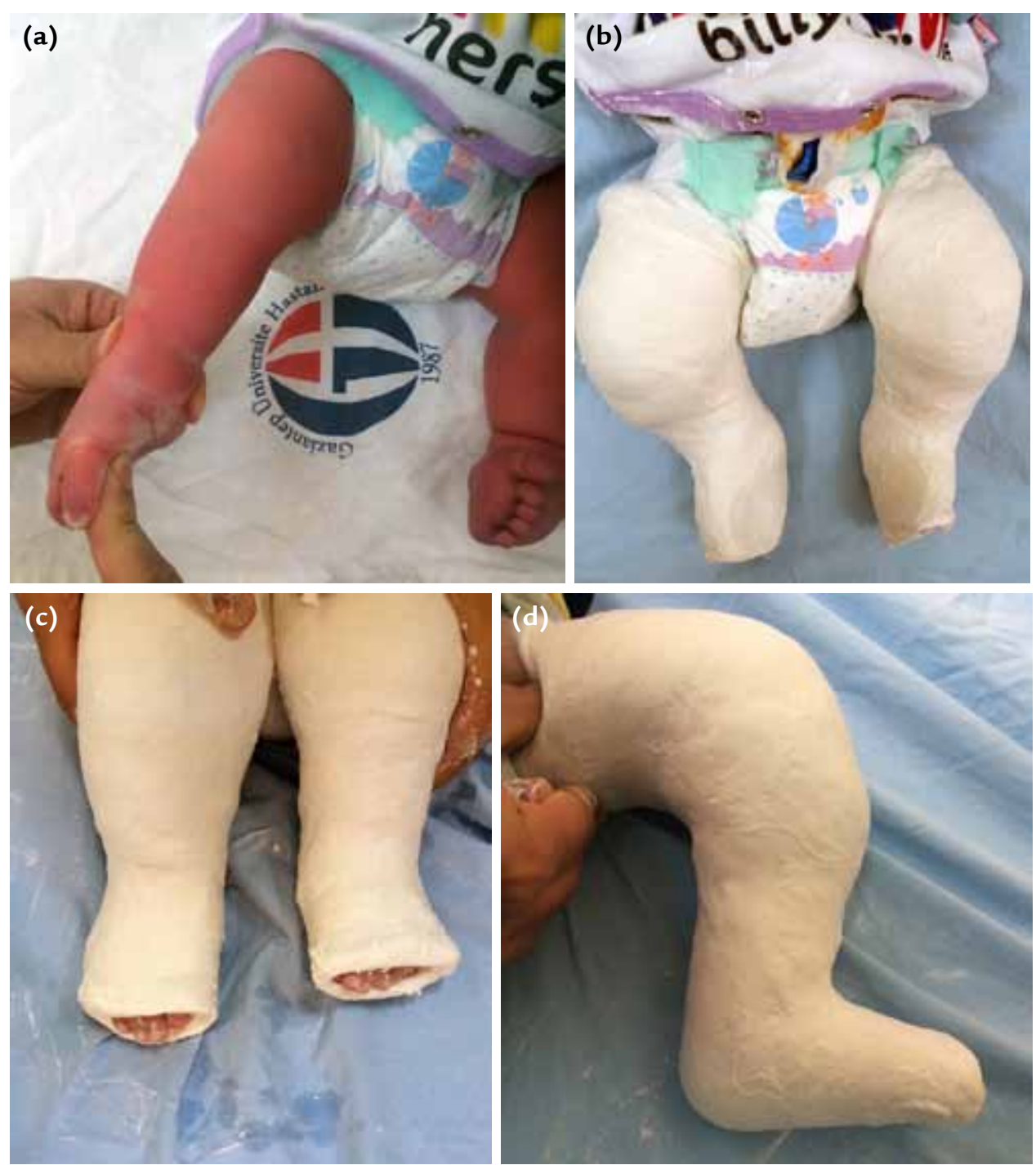

Şekil 3. a-d. Kavusu düzeltmek için birinci metatars başına bastırılması (a), kavusun düzeltildiği ilk alçı (b), adduktus ve varusu düzeltme için yapılan alçı (ekine dokunulmaz) (c) ve ekin düzeltildikten sonra yapılan alçının yandan görünüşü (d).

Alçı diz üstüne uzatılırken, uyluğa sarılan pamuk biraz daha kalın olabilir. Böylece, cildin iritasyon riski biraz daha azalmış olur. ìlk alçı tamamlandığında, karşıdan bakarken ön ayağın tamamen supinasyonda, ayağın ise ekinde olduğu görülecektir. ${ }^{[17]}$

Alçı çıkarma işlemi, yeni alçının yapılacağı ortamda uygulanmalıdır. Aile evde alçıyı çıkarıp geldiğinde, geçen süre boyunca kazanılan düzelmenin çoğu kaybedilebilir. Alçı çıkarılmadan önce 20 dakika kadar ılık suda bekletilerek gevşeme sağlanmalıdır. Alçıyı çıkarmak için alçı bıçağı kullanılması, cilde verilebilecek zarar riskini azaltacaktır. Alçının suda gevşetilmesinin ardından, önce diz üstündeki bölüm, daha sonra diz altındaki bölüm çıkarılmalıdır. ${ }^{[18]}$
Haftalık alçılamalar sonucunda Aşil tenotomisine karar verilirse, uygun şartlar dahilinde cilt üzerine lokal anestezik krem uygulayarak veya tendon çevresine az miktarda lokal anestezik enjekte edilerek, tenotomi uygulanabilir. Üç aylık ve daha büyük bebeklere, ameliyathane şartlarında tenotomi yapılması daha uygun olabilir. Böylece, dirence karşı koymadan daha rahat bir alçılama yapılabilir. Tenotomi sonrası tam düzelme elde edilen hastalarda, üç hafta kadar alçı çıkarılmadan beklenir (Şekil 3). Üç hafta sonunda alçı çıkarıldığında, ayak artık ortez kullanımı için uygun hale gelmiş olacaktır. ${ }^{[19]}$

Düzelmenin devam etmesini sağlamak için geliştirilen çeşitli tipte ortezler bulunmaktadır. Ortez kullanılmayan olgularda yüksek oranlarda nüks bildirilmiştir. 
Seçilen ortez, kullanım ilkelerine göre uygulanmalı ve hafif olgularda iki, ağır olanlarda ise dört yıl kadar kullanıma devam edilmelidir. ${ }^{[20]}$

\section{KAYNAKLAR}

1. Hefti F. Foot and ankle. In: Brunner R, Freuler F, Hasler CC, Jundt G, editors. Pediatric Orthopedics in Practice. Berlin Heidelberg: Springer-Verlag; 2007. p.366-453.

2. Scaduto A. Pediatric Conditions Affecting the Lower Extremity. In: Lieberman JR, editor. AAOS Comprehensive Orthopaedic Review. Rosemont IL: American Academy of Orthopaedics Surgeons; 2009. p.339-58.

3. Wynne-Davies R. Genetic and environmental factors in the etiology of talipes equinovarus. Clin Orthop Relat Res 1972;84:9-13.

4. Staheli LT. Foot. In: Staheli LT, editor. Practice of pediatric orthopedics. Philadelphia: Lippincott Williams \& Wilkins; 2001. p.89-114.

5. Krishna M, Evans R, Sprigg A, Taylor JF, Theis JC. Tibial torsion measured by ultrasound in children with talipes equinovarus. J Bone Joint Surg Br 1991;73(2):207-10.

6. Tachdjian MO. The foot and leg. In: Wickland EH, editor. Tachdjian's pediatric orthopaedics. Vol. 4, 2nd ed. Philadelphia: W. B. Saunders; 1990. p.2405-3012.

7. Ippolito E, Farsetti P, Caterini R, Tudisco C. Long-term comparative results in patients with congenital clubfoot treated with two different protocols. J Bone Joint Surg Am 2003;85-A(7):1286-94.

8. Sanghvi AV, Mittal VK. Conservative management of idiopathic clubfoot: Kite versus Ponseti method. J Orthop Surg (Hong Kong) 2009;17(1):67-71.

9. Ponseti IV, Campos J. Observations on pathogenesis and treatment of congenital clubfoot. Clin Orthop Relat Res 1972;84:50-60.
10. Ionasescu V, Maynard JA, Ponseti IV, Zellweger $\mathrm{H}$. The role of collagen in the pathogenesis of idiopathic clubfoot. Biochemical and electron microscopic correlations. Helv Paediatr Acta 1974;29(4):305-14.

11. Laaveg SJ, Ponseti IV. Long-term results of treatment of congenital clubfoot. J Bone Joint Surg Am 1980;62(1):23-31.

12. Pirani S, Zeznik L, Hodges D. Magnetic resonance imaging study of the congenital clubfoot treated with the Ponseti method. J Pediatr Orthop 2001;21(6):719-26.

13. Shaw NE. The early management of clubfoot. Clin Orthop Relat Res 1972;84:39-43.

14. Bor N, Herzenberg JE, Frick SL. Ponseti management of clubfoot in older infants. Clin Orthop Relat Res 2006;444:224-8.

15. Mangat KS, Kanwar R, Johnson K, Korah G, Prem $H$. Ultrasonographic phases in gap healing following Ponseti-type Achilles tenotomy. J Bone Joint Surg Am 2010;92(6):1462-7. CrossRef

16. Ponseti IV. Clubfoot management. J Pediatr Orthop 2000;20(6):699-700.

17. Morcuende JA, Abbasi D, Dolan LA, Ponseti IV. Results of an accelerated Ponseti protocol for clubfoot. J Pediatr Orthop 2005;25(5):623-6.

18. Abdelgawad AA, Lehman WB, van Bosse HJ, Scher DM, Sala DA. Treatment of idiopathic clubfoot using the Ponseti method: minimum 2-year follow-up. J Pediatr Orthop B 2007;16(2):98-105.

19. Baş EG, Aktekin CN. Ayağın Doğuştan ve Kazanılmış Deformiteleri. İçinde: Çullu E, editor. Çocuk Ortopedisi. İstanbul: Bayçınar Tıbbi Yayıncılık; 2012. p.199-242.

20. Herring JA. Disorders of the foot. In: Herring JA, editor. Tachdjian's Pediatric Orthopedics, 3rd ed. Philadelphia: W. B. Saunders; 2002. p.891-1039. 